\title{
LA INEVITABILIDAD DE LO DICHO
}

\author{
Juan Carlos Aguirre García
}

Resumen: El propósito de este artículo es exponer la tesis levinasiana de la inevitabilidad de lo dicho, teniendo como trasfondo algunas cuestiones epistemológicas que suscita. Para esto, se comienza presentando la contraposición que establece Levinas entre verdad del desvelamiento y verdad del testimonio, destacando sus diferencias más radicales. Posteriormente, teniendo la subjetividad como hilo conductor, se reconstruye el camino que relacionaría ambos tipos de verdad, mostrando cómo la tesis de la inevitabilidad de lo dicho adquiere relevancia en las discusiones epistemológicas. Finalmente, se concluye sugiriendo algunos aportes de esta reflexión para las consideraciones acerca de una racionalidad renovada.

Palabras Claves: Desvelamiento. Epistemología. Racionalidad. Testimonio. Verdad.

\section{INTRODUCCIÓN}

Emmanuel Levinas es reconocido entre la comunidad académica como filósofo de la ética; en efecto, gran parte de los especialistas en el autor se proponen o bien desentrańar las implicaciones de su concepción de la "ética como filosofía primera”, o bien ponerla en discusión con otras propuestas éticas - analíticas o continentales-, o con otros campos, por ejemplo, la política, donde podría jugar algún papel. Ahora bien, ¿cómo podríamos entender la ética de Levinas? En Autrement qu'être ou au-delà de l'essence (en adelante $A E$ ), Levinas (1974, p.189) define la ética de la siguiente manera: "La ética es el campo que dibuja la paradoja de un infinito en relación con lo finito, sin

\footnotetext{
${ }^{1}$ Profesor del Departamento de Filosofía de la Universidad del Cauca, Cauca - Colombia. (D) https:// orcid.org/0000-0003-0938-2730 E-mail: jcaguirre@unicauca.edu.co

Líneas de investigación: fenomenología, epistemología y filosofía de la ciencia. Este artículo hace parte de la investigación doctoral: "Crítica de Emmanuel Levinas a los paradigmas occidentales sobre el conocimiento y posibilidades para una racionalidad renovada en filosofía y en ciencias humanas" (Medellín: Universidad Pontificia Bolivariana, 2012-2017).
}

http://dx.doi.org/10.1590/0101-3173.2019.v42n4.05.p81

This is an open-access article distributed under the terms of the Creative Commons Attribution License. 
desmentirse en esta relación. La ética es el estallido de la unidad originaria de la apercepción trascendental, es decir, lo más allá de la experiencia.” Parece claro que la ética de la que habla Levinas no se corresponde estrictamente con lo que ha dicho la tradición. A este respecto, Perpich afirma:

La moral ilustrada se describe frecuentemente como preocupada con la pregunta: “¿Qué debo hacer?” Por otro lado, la ética antigua se identifica por hacer preguntas más amplias: “¿Cómo se debe vivir?” o “¿cuál es la mejor vida para los seres humanos?” En ocasiones, estas preguntas se presentan como marcando puntos finales en el continuo por el que transcurre la investigación ética [...] La noción levinasiana de responsabilidad infinita no responde claramente a ninguna pregunta de este tipo, ni puede ubicarse adecuadamente en ningún punto de dicho continuo. (PERPICH, 2008, p. 3).

Un poco más adelante, mientras considera a la alteridad como "el problema de la trascendencia", la propia Perpich (2008, p. 49) sostiene que, en Levinas, "la trascendencia funciona como un tropo para expresar la inadecuación de toda representación en la singularidad del otro que está frente a $m i "$ "énfasis en el original). Si esto es así, podríamos repetir la pregunta con la que Perpich introduce su libro The ethics of Emmanuel Levinas (2008), esto es, podríamos preguntar: “¿Pero, esto es ética?” No quiero entrar a responder esa pregunta. Mi interés está más bien en sugerir, siguiendo a Bernasconi (2005), que la búsqueda que guió todo el trabajo de Levinas no fue tanto la ética sino la trascendencia; en tal sentido, se podría tratar de descentrar, así sea metodológicamente, la persistencia que los estudiosos del autor tienen respecto a la ética, de modo que se consideren otros asuntos que traten de clarificar la viabilidad de la trascendencia, o mejor, de la "significación ética de la trascendencia" (LEVINAS, 1996, p. 257), tal y como Levinas la considera.

Teniendo lo anterior como presupuesto, este trabajo revisará la diferencia que establece Levinas (1972/1997) entre Verdad del desvelamiento y verdad del testimonio, en un artículo que lleva ese mismo título, a la luz del capítulo 5 de $A E$, titulado: "Subjectivité et infini". En vez de enfatizar en las diferencias radicales entre ambos tipos de verdad, el propósito será mostrar la posibilidad, más aún la necesidad, que tiene para Levinas (1974, p. 20) la "tematización, el pensamiento, la historia y la escritura", es decir, resaltar la idea levinasiana de la inevitabilidad de lo dicho o la "tematización inevitable para que la propia significación se muestre” (LEVINAS, 1974, p. 193). Se espera que el énfasis en esta idea permita sugerir algunas posibilidades que abre 
Levinas para una racionalidad renovada, especialmente en cuestiones clásicas de la epistemología o la teoría del conocimiento y de las ciencias humanas.

Para lograr este propósito, el trabajo se dividirá en tres secciones: en la primera, se identificarán las tesis relevantes del capítulo 5 de $A E$, estableciendo la inconmensurabilidad entre la verdad del desvelamiento y la verdad del testimonio; en la segunda, se presentarán los modos como Levinas relaciona el decir (dire) con lo dicho (dit), esto es, cómo intenta suturar o anudar [point de rupture mais aussi de nouement (LEVINAS, 1974, p. 15)] dicha inconmensurabilidad; finalmente, la tercera sección sugerirá, a modo de conclusión, alguna posibilidad que estas ideas abren para las cuestiones mencionadas en el párrafo anterior. En tanto el interés está guiado por el afán de esclarecer sus aportes para una racionalidad renovada, se dejará de lado buena parte de las cuestiones que podrían parecer relevantes a muchos estudiosos, centrándome exclusivamente en aquellas ideas que contengan pertinencia en el contexto epistemológico general o de las ciencias humanas.

\section{Verdad Del DesVELAMiento Y VERDAD DEL TESTIMONio}

En 1972, Levinas publicó el artículo que tiene por título "Vérité du dévoilement et vérité du témoignage" (1972/1997). Posteriormente, en 1974, publica $A E$. Allí, en la Nota preliminar, menciona dicho artículo afirmando que en él "figuran las páginas esenciales de nuestro capítulo V" (LEVINAS, 1974, p. ix). Como es bien sabido, gran parte de $A E$ condensa artículos previamente publicados; no obstante, como el mismo autor sostiene, "este libro no es una recopilación de artículos" (LEVINAS, 1974, p. ix). Podría encontrarse argumentos que desafiaran esta creencia del autor (máxime cuando él afirma a renglón seguido que "los rastros de esta autonomía [de los artículos] no siempre han sido borrados de la actual versión”), pero habría más razones para considerar la unidad temática de la obra, más aún, su estructura. En efecto, recientemente se editó una serie de lecciones de Simon Critchley sobre Levinas, bajo el título The problem with Levinas (2015); allí, en la tercera lección, el profesor Critchley (2015, p. 81) dice que $A E$, "aunque es un libro mucho menos sistemático [en comparación con Totalité et infini], tiene una clara estructura”. Me gustaría citarla, en razón de su sencillez:

La introducción (capítulo uno) establece todo el argumento e introduce los términos y conceptos centrales [...] El capítulo dos [...] es un movimiento en el que vamos de la intencionalidad, es decir, de una comprensión de la conciencia y de la relación de la conciencia con los objetos, $a$ un argumento 
por la sensibilidad [...] El capítulo tres [...] significa que, para Levinas, la estructura profunda de la sensibilidad es la proximidad con el otro [...] En el capítulo cuarto, "Sustitución", la estructura profunda de la proximidad se revela como sustitución [...] En el capítulo quinto, después de haber reducido lo dicho de la filosofía a esta noción de sustitución, que es el decir del libro, Levinas retorna a lo dicho en una explicación de la justicia, el tercero y todo lo demás. Esto es lo que llamo: "lo dicho justificado"; es decir, lo dicho que se justifica con referencia al decir que respira a través de él. (CRITCHLEY, 2015, p. 81-82).

De acuerdo con esta estructura, el presente artículo se inserta en lo denominado por Critchley "lo dicho justificado"; la inevitabilidad de lo dicho, entonces, adquiere un matiz en la macro discusión decir-dicho. Justamente, la consideración en esta sección de los dos tipos de verdad se articula a tal macro discusión, siendo metodológicamente necesario plantearlos como dos tipos distintos, incluso inconmensurables, de verdad. Ahora bien, es preciso advertir que, a diferencia de otros textos (por ejemplo Totalité et infini, 1961) en los que Levinas reconstruye la tradición epistemológica sobre la verdad como adecuación y plantea (aunque ambiguamente) su concepción de verdad, tanto en el artículo de 1972 como en $A E$ la consideración de la verdad se da en términos de subjetividad, más específicamente, Levinas (1974, p.167) examina "la implicación del sujeto en la significación"; este es el criterio con el que comparará ambos tipos de verdad.

Levinas analiza la verdad por desvelamiento bajo tres categorías: la objetividad, el sistema y la absorción del sujeto en lo dicho. Para analizar la objetividad, Levinas (1972/1997, p. 179) parte de la relación verdad-ser, siendo lo verdadero sinónimo de lo real; en este sentido, el ser aparece al sujeto y este establece la verdad acerca del ser. No obstante, el establecimiento de la verdad, su justificación, si bien es una potestad del sujeto, está circunscrita al aparecer del ser; en últimas, la justificación del conocimiento de la realidad se logra solo en la medida en que concuerde con el modo como es la realidad ${ }^{2}$. Si el sujeto

2 Es claro que Levinas está sosteniendo aquí una teoría correspondentista de la verdad. Según David (2016), la teoría de la verdad por correspondencia "es toda perspectiva que adopte explícitamente la idea que la verdad consiste en una relación con la realidad, es decir, que la verdad es una propiedad relacional que implica una relación característica (a especificar) con alguna porción de la realidad (a especificar)". Más adelante, David agrega: "En años recientes, estos competidores [a la teoría de la verdad por correspondencia] han sido prácticamente reemplazados [...] por las teorías deflacionarias de la verdad y, en menor medida, por la teoría de la identidad (nótese que estos nuevos competidores no se asocian típicamente con el antirrealismo).” La referencia a David permite extraer algunas conclusiones: 1. Que Levinas está confrontando un tipo de verdad (la correspondentista), no todo tipo de verdad; 
afirma algo acerca de la realidad, pero no hay nada en la realidad que sustente tal afirmación, lo enunciado por el sujeto debe tomarse como un sinsentido. La objetividad consistiría, entonces, en justificar a partir de evidencias, en refrenar el impulso de ir más allá de ellas. Levinas (1974, p.168) lo enuncia de este modo: "La objetividad tiene que ver con el ser de las entidades que porta -significa la indiferencia de lo que aparece a su propio aparecer." Lo que Levinas denomina "indiferencia" podría equivaler a la neutralidad valorativa que, todavía hoy, parece consustancial a la actividad científica ${ }^{3}$. La conclusión que extrae Levinas (1974, p. 168) es que "la subjetividad en tanto que saber se subordina, pues, al sentido de la objetividad”.

Ahora bien, la subordinación de la subjetividad a la objetividad se condensa en lo que Levinas denomina: el sistema. En este punto, sus análisis describen con precisión el modo como la ciencia, modelo de verdad por desvelamiento, se organiza para dar cuenta de todo. Los elementos de este orden serían: los términos y las relaciones entre los términos, las estructuras y el sistema. Levinas destaca una mutación que parte de las relaciones y culmina en la "estructura sistemática de la totalidad" (LEVINAS, 1974, p. 169); sin embargo, lo sorprendente es que este punto final logra consolidarse como el determinador de lo que se puede pensar y en las formas como se debe pensar. En palabras de Levinas, el sistema se convierte en la inteligibilidad o, mejor, lo inteligible es aquello que puede pensarse en los límites del sistema: "La inteligibilidad o la estructura sistemática de la totalidad dejará aparecer la

2. Que Levinas no es el único en hacer esta crítica a la teoría de la verdad por correspondencia; más aún, en el contexto de la epistemología, los críticos y alternativas abundan; 3. Que si bien no podría relacionarse estrictamente la tesis levinasiana de la "verdad del testimonio" con algún tipo de verdad formulado en la epistemología contemporánea, podría intentarse una relación amplia. No es casual que la traducción al inglés del artículo de 1972 se haya publicado en una compilación agrupada bajo el título Truth, engagements across philosophical traditions (2005), donde aparecen epistemólogos de la talla de Davidson, Putnam, Rorty, McDowell. Finalmente, 5. Que por criticar la teoría de la verdad por correspondencia, Levinas no tendrá que defender, necesariamente, el antirrealismo.

${ }^{3}$ Reiss y Sprenger (2016) definen la objetividad científica en términos similares a los descritos por Levinas: "La objetividad científica es una característica de los enunciados, métodos y resultados de la ciencia; expresa la idea que los enunciados, métodos y resultados de la ciencia no están, o no deberían estar, influenciados por perspectivas particulares, juicios de valor, opiniones comunes o intereses particulares, por nombrar algunos factores relevantes. Con frecuencia se considera a la objetividad como un ideal de la investigación científica, como un buen criterio para evaluar el conocimiento científico y como el fundamento de la autoridad que tiene la ciencia en la sociedad". No obstante, el término indiferencia (indifférence), más que neutralidad, Levinas lo confronta, sin que haya una contraposición estricta (es bien sabida su aversión a la lógica amparada en el principio de no contradicción), con no in-diferencia (non-indifférence) que le permite tanto bloquear la actitud típica de la objetividad (o mejor, del objetivismo), como señalar, por doble negación, el carácter de la verdad del testimonio: la diferencia (différence) o separación. 
totalidad y la protegerá de toda alteración que le pueda venir de la mirada." (LEVINAS, 1974, p. 169). Ahora bien, Levinas encuentra una grieta en este proceso, a saber, que las estructuras no pueden dar cuenta, plenamente, de lo que aparece: "Un orden manifestado, en el que los términos de las estructuras o los elementos de un sistema se mantienen a título de abstracción, es aún oscuro y, no obstante, su tematización, ofrece resistencia a la luz; es decir, no es plenamente objetivo." (LEVINAS, 1974, p. 169; énfasis mío). La fragilidad de la objetividad sobre la que se levanta el sistema, no es óbice para que se cuestione su inteligibilidad; al contrario, es una motivación para que los investigadores reparen las grietas, de modo que lo externo al sistema pueda encontrar en él su lugar. Es en este punto donde Levinas (1974, p. 171) afirma que la subjetividad misma queda subsumida en este proceso de inteligibilidad del ser: "La subjetividad del sujeto siempre consistirá en borrarse ante el ser, en dejarlo ser reuniendo las estructuras en significación, en proposición global dentro de un dicho, en un gran presente de la sinopsis donde el ser brilla en todo su esplendor."

Las consideraciones que hace Levinas tanto de la objetividad como del sistema sirven como premisas que respaldan su tesis que el sujeto se absorbe en lo dicho. Las consecuencias que podrían extraerse de esto serían: 1) El sujeto estaría limitado en su comunicación interhumana, ya que "no sería la fuente de ninguna significación -independientemente de la verdad de la esencia a la cual sirve" (LEVINAS, 1974, p. 171). 2) Lo que cuenta como sentido tendrá que someterse al escrutinio del sistema: "Toda dia-cronía radical -que no se pueda agrupar- se excluye del sentido." (LEVINAS, 1974, p. 172). Finalmente, 3) la verdad como desvelamiento, fundamento del sistema, requiere una subjetividad reducida: "El psiquismo sería conciencia que excluye todo traumatismo, pues el ser es, en efecto, lo que se muestra antes

\footnotetext{
${ }^{4}$ Los análisis levinasianos sobre el sistema podrían tener relación con los análisis que hace Kuhn (1996), especialmente en lo concerniente a la ciencia normal. Los conceptos de paradigma y enigma (problemática traducción al castellano de puzzle) permiten clarificar lo que Levinas entiende por inteligibilidad y cómo esta no es desafiada por los enigmas; al contrario, la solución de enigmas permite que el paradigma se consolide y siga manteniendo su carácter de criterio para determinar qué cuenta como problema de investigación. En palabras de Kuhn: "Una de las cosas que adquiere una comunidad científica con un paradigma es un criterio para seleccionar problemas que, mientras se dé por sentado el paradigma, puede suponerse que tienen soluciones. En gran medida, estos son los únicos problemas que la comunidad admitirá como científicos o animará a sus miembros a tratar de resolver. otros problemas, incluyendo muchos que previamente se han establecido, se rechazan como metafísicos, como asuntos de otra disciplina o, a veces, como demasiado problemáticos como para justificar el tiempo empleado en ellos." (KUHN, 1996, p. 37).
} 
de herir, lo que amortigua su violencia en conocimiento (savoir)." (LEVINAS, 1974, p. 172).

La pretensión de Levinas es, precisamente, controvertir esta visión de subjetividad, a partir de lo alcanzado en los capítulos previos de $A E$, especialmente en el 4, dedicado a la cuestión de la sustitución, tema que, si bien queda por fuera de nuestro alcance en este momento 5 , Levinas reconstruye, en sus líneas básicas, en el capítulo 5. Es natural, entonces, que ante la pretensión de identificar la significación con la inteligibilidad que brota de "los modelos del ser y de la correlación sujeto-objeto" (LEVINAS, 1974, p. 173), Levinas (1974, p. 173) anteponga la sustitución: "Matriz de toda relación tematizable, el uno-para-el-otro o la significación -el sentido o la inteligibilidad- no reposa en el ser." Sin embargo, no se trata solo de una antítesis a la verdad del desvelamiento; lo que Levinas está sosteniendo es que el uno-para-el-otro es la fuente de la significación. ¡Esto es, cuando menos, asombroso! A no ser que moderemos la proposición, por ejemplo, tratando de darle un sentido metafórico, no podría entenderse cómo conceptos, como la verdad, dependerían de la relación del uno-para-el-otro. No obstante, Levinas (1974, p.174) lo remarca: "El uno-para-el-otro, [es el] fundamento de la teoría en tanto que hace posible la relación y el punto fuera del ser, el punto del desinterés necesario para una verdad que no quiere ser pura ideología." Es en este contexto en el que despliega su tesis de la verdad del testimonio.

El argumento parte de una conjetura: “ $¡$ No puede pensarse el psiquismo como una relación con lo no-representable, con un pasado más acá de todo presente y toda representación que no pertenecen al orden de la presencia?" (LEVINAS, 1972/1997, p. 183; traducción ligeramente modificada). Podría decirse que toda la obra de Levinas se ha orientado a postular esta posibilidad; en consecuencia, responderá afirmativamente a esta pregunta. El acontecimiento que encuentra Levinas y que sirve de experimentum crucis para respaldar su conjetura es la "responsabilidad para con los otros hombres"

\footnotetext{
${ }^{5}$ Una aproximación introductoria al asunto puede encontrarse en Aguirre (2012).

${ }^{6}$ Esta idea requerirá más desarrollo; sin embargo, es preciso insinuar que la propuesta levinasiana estaría ofreciendo nuevas rutas a las discusiones en torno al compromiso que tienen las teorías con la realidad, específicamente aquellas que tratan de definir las teorías como "descripciones generalizadas verdaderas de la realidad" (definición que hace Van Fraassen (1980, p. 7) de la posición del realismo científico, a la que controvierte con su empirismo constructivo), obviando la posibilidad de que no todo lo enunciado en la teoría pueda coincidir con el ser / realidad, esto es, desechando la idea de que pueda haber, por ejemplo, "ficciones útiles" en la teoría. En segundo lugar, parece haber en Levinas la preocupación por la relación verdad - ideología, pero su intención no estaría tanto del lado de las contemporáneas versiones hostiles a la ciencia, sino que adoptaría una perspectiva de recomposición.
} 
(LEVINAS, 1972/1997, p. 183). A partir de este acontecimiento, que tiene las características de "cotidiano y extra-ordinario", Levinas cuestiona la objetividad, el sistema y la subjetividad propias del contexto de la verdad del desvelamiento.

Como es habitual, Levinas aborda la responsabilidad mediante una via negativa: "no comienza en mí", "no es presente", "no es representable"; todos estos conceptos fueron ampliamente desarrollados a lo largo de su trayectoria académica. Sin embargo, en tanto centrado en la subjetividad, este instrumental teórico le permite poner en cuestión el concepto de subjetividad que ha predominado en la tradición filosófica occidental, a saber, la propia de un sujeto anclado en su identidad. Según Levinas (1972/1997, p. 183), a partir de la responsabilidad para con el otro hombre, "[el sujeto] se alienaría en el trasfondo de su identidad, de una alienación que no vaciaría a lo mismo de su identidad, pero lo obligaría en la asignación irrecusable de mí por el otro, donde nadie podría sustituirme". Esta situación de alteridad en la identidad es denominada por Levinas: inspiración. De acuerdo con esto, la estructura de la subjetividad no comienza con el reconocimiento que el sujeto hace de sí como sí mismo; previo a ello se encuentra, en un extraño sentido de previo que rompe la linealidad del tiempo, desde un tiempo inmemorial, el llamado que otro ${ }^{8}$ le hace a mismo obligándole a responder. Es justamente este carácter de obligación lo que impide que mismo se dé la libertad de sopesar si se compromete o no; en tanto previo al presente y a la representación, mismo no puede más que responder.

Si bien el abordaje de la responsabilidad lo hace Levinas a partir de una via negativa, que conserva los ecos de Totalité et infini, la responsabilidad misma es tratada en $A E$ mediante una via eminentiae, pues Levinas (1972/1997, p.

\footnotetext{
7 Este aparente oxímoron está en consonancia con el carácter enigmático y ambiguo que parece requerir la formulación de la verdad del testimonio; el riego de enunciar un acontecimiento que no es tematizable, pero que aún así necesita de traducción (traición). Algunos autores, por ejemplo Smith, resaltan este carácter retórico de $A E$ : "Es precisamente a la apreciación problemática de la retórica que Levinas hace una gran contribución, pues toda su filosofía es deliberada y autoconscientemente 'retórica' en el sentido que hemos tratado de dar aquí." (SMITH, 1986, p. 68). Del mismo modo, Critchley (2015, p. 68) afirma que "una manera útil de pensar sobre Levinas es no pensarlo en términos de argumentos o proposiciones a verificar, sino en relación con cierta acumulación de términos, una intensificación retórica a través de la repetición, la invocación y la multiplicación. Levinas es un pensador rapsódico". No obstante, estas afirmaciones hay que tomarlas cum grano salis.

8 Adopto la utilización de mismo y otro que hace García-Baró (2012) en su traducción de Totalité et infini, esto es, sin artículos. Al respecto, el filósofo español advierte: "Siempre que sea posible, prescindiré del artículo y escribiré ‘mismo’ y 'otro' (u 'otro').” (GARCÍA-BARÓ, 2012, p. 10). La razón podría ser tratar de salvaguardar ambos términos de la sustantivación.
} 
184) reconoce que "la responsabilidad va positivamente hacia el otro." "Aparece aquí una interesante relación que, a mi modo de ver, permite comprender dos expresiones levinasianas susceptibles de malas interpretaciones: gloria del infinito (la glorie de l'infini) y testimonio (témoignage). La relación se establece entre los términos: proximidad, obligación, obediencia, responsabilidad. Otro, próximo a mismo, se impone a la seguridad de mismo, "deslizándose en mí como un ladrón” (LEVINAS, 1974, p. 191); otro obliga a mismo antes de cualquier deliberación de mismo, antes siquiera de que mismo se comprometa, pasividad; mismo traumatizado que obedece y, en consecuencia, es responsable por otro. El punto nuclear de esta relación, el hilo que desenreda el ovillo, es: la responsabilidad no cesa; no hay un punto en el que mismo pueda determinar un "hasta aquî"; en tanto la responsabilidad no brota de mismo, su respuesta siempre será: "Heme aquí." (LEVINAS, 1974, p. 190). La constante sería: entre más obedezco, más estoy obligado a responder, y así ad infinitum.

Con esta relación como trasfondo, donde la responsabilidad se torna eje articulador, se podría clarificar el sentido de los términos gloria del infinito y testimonio. Gloria del infinito, entendida como esplendor del infinito ${ }^{10}$, indicaría que es en la responsabilidad por el otro donde el infinito se muestra en su mayor lucimiento (que no es lucidez). El esfuerzo hecho por Levinas en Totalité et infini para presentar la idea de infinito ${ }^{11}$, respaldado en su lectura sui generis de la tercera meditación cartesiana, encontraría aquí su máximo brillo; es como si hubiera encontrado el caso o la instancia perfecta para decir: "Responsabilidad, esa es la traducción más precisa de infinito." Ahora bien, este acontecimiento en el que el infinito se pasa (se passe) en la responsabilidad de mismo por otro, pero que conserva su separación absoluta (illéité), no puede ser descrito por mismo como un tema; cualquier palabra que se enuncie empañaría, traicionaría el esplendor del infinito. En vez de sujeto activo que enuncia alguna "información", "expresión”, "repercusión” o "síntoma” de la experiencia del infinito, el sujeto se torna un testigo del infinito que se pasa en él y que se gloría en la responsabilidad por el otro. En tal sentido, se llegaría a

\footnotetext{
${ }^{9}$ La distinción entre la via negativa y la via eminentiae, así como la sugerencia de relacionar la primera con la obra de 1961 y la segunda con $A E$, se toman de Smith (1986). No obstante, no me comprometo con su conclusión, esto es, no considero que en Levinas haya una reivindicación de la retórica, no importa el sentido que a esta quiera darle Smith.

${ }^{10}$ La cuarta acepción que el DRAE trae para Gloria es: "Majestad, esplendor, magnificencia".

${ }^{11}$ Me refiero específicamente al apartado: "La transcendance comme idée de l'infini." (LEVINAS, 2006, p. 39-45).
} 
una conclusión problemática ${ }^{12}$ : la responsabilidad por el otro me hace testigo del infinito; mi testimonio no tiene que decir nada, la responsabilidad es mi testimonio. La verdad del testimonio es la responsabilidad por el otro.

Lo problemático del asunto es que se trataría de una verdad sin enunciados (en la terminología levinasiana sería: un "decir sin dicho" (LEVINAS, 1974, p. 187); no se trata de utilizar un nuevo lenguaje, por ejemplo, el poético, que haga justicia con el decir del infinito; ningún lenguaje daría cuenta del infinito. Lo que Levinas estaría proponiendo se ubicaría antes de todo lenguaje. Así parece concluirse de la siguiente respuesta dada en una entrevista:

Creo que el comienzo del lenguaje está en el rostro. De cierta manera, digamos, en su silencio. Reaccionas al otro con una respuesta; no solo una respuesta, sino una responsabilidad. Estas dos palabras [réponse, responsabilité] están estrechamente relacionadas. El lenguaje no comienza con signos que se dan, con palabras. El lenguaje es, sobre todo, el estar orientados hacia... lo que significa decir mucho más que lo dicho. (LEVINAS, 2003, p. 169-170).

En su versión más pura, entonces, la verdad del testimonio es aquella en la que el infinito se pasa; esto solo ocurre cuando acontece la "abertura de sí, como imprudente exposición al otro, pasividad sin reserva hasta la sustitución y, por consiguiente, exposición de la exposición” (LEVINAS, 1974, p. 192). El que el infinito se pase, implica que no es posible, a riesgo de traicionarlo, tratarlo como un tema; en este contexto, el infinito sería una "causa errante" inscrita en mí (LEVINAS, 1974, p. 192). ${ }^{13}$ En tal sentido, en este tipo de verdad la significación no puede fundarse en el ser o en la representación que me hago del ser, sino en el decir que es sustitución, responsabilidad por el otro; por tanto, en la verdad del testimonio el decir es signo, que significa aunque no diga una palabra.

Se ha visto en este apartado que Levinas confronta dos tipos de verdad: la del desvelamiento y la del testimonio. En el primero, hay una borradura del sujeto en aras del ser y su manifestación; los enunciados verdaderos coincidirían con la manifestación del ser, con dejar que el ser se muestre. Se trataría de una

\footnotetext{
${ }^{12}$ Ciertamente, Levinas (1974, p. 190) lo prevé: “QQué decepción para los amigos de la verdad tematizadora del ser y del sujeto que se diluye ante él!"

${ }^{13}$ En este punto, Levinas menciona el importante asunto de la huella (la trace), desplegado ampliamente en Levinas (1998). El tema por sí mismo exigiría, en términos epistemológicos, un tratamiento detallado. Por lo pronto, remito al artículo de Navia (2010).
} 
verdad circunscrita al terreno epistemológico-ontológico, donde la verdad del enunciado depende de su adecuación con lo real. En el segundo, el sujeto se altera por el infinito, reconociendo que cualquier enunciado que pronuncie se quedará corto ante el esplendor de tal infinito; no se trata de una imposibilidad del sujeto, como una carencia, sino del acontecimiento mismo del infinito que desborda toda pretensión tematizadora. El indicio de esta alteración lo constituye la responsabilidad por el otro, que no deja al sujeto tranquilo en su morada, sino que le obliga a salir de sí, a exponer-se. La responsabilidad por el otro se ubica en un terreno previo al epistemológico-ontológico de la verdad por desvelamiento; se ubica en el terreno de la ética. Más que en la verdad o el ser, la verdad del testimonio se ubica en el territorio del bien, en lo más allá del ser. Pero, ¿por qué seguir insistiendo en llamarlo verdad del testimonio?

\section{2 “LA SABIDURía Del AMOr AL SERViCIO DEL AMOR”}

El apartado anterior presentó dos tipos de verdad expuestos por Levinas: una verdad acorde con la tradición epistemológica occidental y una verdad que dicha tradición pondría entre comillas, como si este nombre se estuviera adulterando. En efecto, se ha considerado que cuestiones como conocimiento, justificación, verdad, prueba, realidad, pertenecen al ámbito de la epistemología o de la ontología; mientras que la responsabilidad, el unopara-el-otro, la bondad, pertenecen al ámbito de la ética o de la teología. ¿Al usar el término verdad, tal y como se presentó en la verdad del testimonio, no estaría Levinas cometiendo un error categorial? Así parece asumirlo, solapadamente, buena parte de los estudiosos de Levinas, al considerar estas tesis en el estricto marco de la ética (sea esto lo que signifique en Levinas) o, a lo sumo, de la política. La falta de estudios sobre la verdad del testimonio en el contexto epistemológico parece indicar que o bien no tendría relevancia en tal contexto, o bien no sería posible darle tal tratamiento sin pervertir las tesis levinasianas. En este apartado intentaré defender que la consideración epistemológica de la verdad del testimonio es una consecuencia necesaria del planteamiento de Levinas y, en cuanto tal, requiere de más atención y análisis.

Lo primero que debe decirse a favor de una lectura de la verdad del testimonio en clave epistemológica se desprende del propio Levinas, específicamente de un "problema metodológico" con el que se encuentra:

Tal problema consiste en preguntarse si lo pre-original del decir (si la anarquía, lo no-original como lo designamos) puede ser conducido a 
traicionarse al mostrarse en un tema (si una an-arqueología es posible) y si tal traición puede reducirse; es decir, si se puede al mismo tiempo conocer (savoir) y liberar a lo conocido (le $s u$ ) de las marcas que la tematización le imprime subordinándolo a la ontología. (LEVINAS, 1974, p. 8).

En el contexto de la verdad del testimonio, el problema abordaría el modo como tal verdad podría ofrecer conocimiento, sin quedar reducida a verdad del desvelamiento, es decir, sin depender únicamente del ser y sin subsumir la subjetividad en dicho ser. Con otras palabras, cómo conservar el carácter propio de toda verdad, es decir, establecer una relación entre términos, sin que los términos se agoten en ella. Este problema metodológico indica que, para Levinas, una salida satisfactoria no podría ser declarar la independencia de ambos tipos de verdad; tampoco que la verdad del desvelamiento encuentre un auxilio de la verdad del testimonio, una especie de complemento; la tesis de Levinas consistirá en acentuar el modo como la verdad del testimonio, consciente de la traición que implica enunciar algo acerca del infinito, tiene que buscar los modos de reducir tal traición. Para Levinas (1974, p. 8), esta es "probablemente [...] la tarea misma de la filosofía".

Ahora bien, ¿por qué no dejar ambas esferas en su inconmensurabilidad? ¿Acaso el infinito no se muestra en su esplendor en la responsabilidad de mismo por otro? ¿Acaso esta responsabilidad no es el decir puro, silencioso, no necesitado de otros signos en tanto es en sí misma un signo? ¿Para qué palabras? ¿No basta la responsabilidad sin porqué? Lo atractivo del argumento levinasiano consiste en prever que su verdad del testimonio, en estado puro, solo aplicaría a la relación mismo-otro, en la singularidad de los términos; no obstante, no solo me encuentro a otro singular, sino que está el otro del otro, denominado por Levinas: el tercero (le tiers). Es en razón de este factum $^{14}$ que se hace necesario legitimar epistemológicamente la verdad del testimonio. En palabras de Levinas:

El tercero introduce una contradicción dentro del decir, cuya significación frente al otro marchaba hasta ahora en un sentido único. Es por sí mismo límite de la responsabilidad, nacimiento de la cuestión: ¿Qué deberé hacer con justicia? Cuestión de conciencia. Se hace necesaria la justicia, es decir, la comparación, la coexistencia,

\footnotetext{
${ }^{14}$ Es arriesgado usar esta palabra para designar al tercero; no obstante, puede conservarse matizando que el otro no se presenta como "un hecho empírico" (LEVINAS, 1974, p. 201) sino que se presenta del mismo modo que el otro próximo, esto es, con las características de "obsesión" que superan la recepción en la sensibilidad.
} 
la contemporaneidad, la reunión, el orden, la tematización, la visibilidad de los rostros $\mathrm{y}$, por tanto, la intencionalidad y el intelecto y, en la intencionalidad y el intelecto, la inteligibilidad del sistema; por consiguiente, también una copresencia sobre un pie de igualdad como ante una corte de justicia. (LEVINAS, 1974, p. 200).

Muchos han visto en la aparición del tercero una legitimación de la política en la obra levinasiana, tal vez por su apelación a la justicia ${ }^{15}$; muchos han pasado por alto expresiones marcadamente epistemológicas como: comparación, orden, tematización, intencionalidad, intelecto; tal vez por la misma razón: por creer que justicia no tiene nada que ver con conocimiento. No obstante, el desafío levinasiano, desde Totalité et infini ${ }^{16}$, consiste en plantear que uno de los conceptos más queridos de la epistemología contemporánea, a saber, la justificación, está precedido por el sentido de justicia, precedencia no solo etimológica sino, ante todo, epistemológica. ${ }^{17}$

Si la cuestión es metodológica, entonces, ¿qué camino (método) propone Levinas? Para Levinas (1974, p.205), el camino (la voie) va "de la responsabilidad al problema”. Este sería su método. De acuerdo con esto, si la significatividad alcanza su pleno sentido en la responsabilidad por el otro, esto es, si la razón es uno-para-el-otro ${ }^{18}$; y si, además, esta responsabilidad por el otro, ante la proximidad del tercero, es quien da sentido a la pregunta "¿qué deberé hacer con justicia?” (LEVINAS, 1974, p. 200), puede concluirse que la primacía la tendría la justicia o, como lo plantea explícitamente Levinas (1974, p. 204), "el fundamento de la conciencia es la justicia”. En tal sentido, los problemas no brotan de un sujeto que cuestiona desde la atalaya de su conciencia, sino que sus preguntas se desprenden de la irrupción de otro que exige a mismo una respuesta, que le exige hacerse responsable. Entonces, no todo enunciado está circunscrito al ámbito del Ser y a la verdad desvelada; o lo que es lo mismo, no todo enunciado es la simple constatación que hace un sujeto acerca de la verdad fidedigna del ser. Antes que al ser, el sujeto está obligado a ser responsable por el otro. ${ }^{19}$

\footnotetext{
${ }^{15}$ Algunos trabajos relevantes al respecto son: Bergo (1999), Bernasconi (1999), Castro (2014).

${ }^{16}$ Véase especialmente la sección: "Verité et justice" (LEVINAS, 2006, p. 80-104).

${ }^{17}$ Un excelente trabajo a este respecto lo constituye Doukhan (2014).

${ }^{18}$ Ver el texto de Smith (1986) que lleva por título, justamente: "Reason as one for another".

${ }^{19}$ Levinas (1974, p. 207) sostiene a este respecto que "ni el realismo ni el idealismo, hermanos gemelos, tienen derecho de primogenitura".
} 
Antes de extraer algunas consecuencias que esta inversión metodológica comporta, es preciso mencionar brevemente dos aspectos. En primera instancia, se requiere elaborar una fina conceptualización epistemológica de lo que Levinas considera como ambivalencia, ambigüedad o enigma; todos estos términos engarzados en la palabra "diacronía". Si bien Levinas ya había tematizado el asunto, ${ }^{20}$ con la irrupción del tercero este alcanza la madurez para considerarlo epistemológicamente. De manera específica, habría que plantear la relación entre el carácter enigmático del decir, enigma que supera la dicotomía visible-invisible, cognoscible-incognoscible, preservando la trascendencia del infinito, y las relaciones que entreteje con la representación, el logos, la conciencia, el trabajo, la noción neutra, el ser. En segunda instancia, es importante resaltar que Levinas indica una labor esencial de la filosofía (y por extensión de las ciencias humanas que partan de la responsabilidad por el otro como fuente de significación ${ }^{21}$ ), a saber, su rol vigilante de poner en cuestión lo dicho, de desdecir lo dicho, de desafiar la verdad establecida, no importando que la fuerza de esta verdad se imponga, pues la certeza de una nueva arremetida crítica está siempre presente. ${ }^{22}$

¿Qué consecuencias pueden extraerse de la inversión metodológica levinasiana? Una primera consecuencia sería que, en razón del tercero, no es posible renunciar a la enunciación; no obstante, la enunciación siempre tiene el riesgo de traicionar el decir. Frente a este riesgo estaría la justicia quien "modera y mide la sustitución por mí al otro y [...] restituye el sí mismo al cálculo" (LEVINAS, 1974, p. 202). Una segunda consecuencia consistiría en propiciar una perspectiva no adversa a la ciencia o anticientífica. La adopción de la responsabilidad para con el otro como fuente de significación permitiría a la filosofía ajustar ciertas pretensiones de la verdad del desvelamiento: "El extraordinario compromiso del otro frente al tercero invoca [...] la comparación y el tener, el pensamiento y la ciencia, el comercio y la filosofía $\mathrm{y}$, al margen de la anarquía, la búsqueda de un principio." (LEVINAS, 1974, p. 205; énfasis mío). A partir de esto se entendería la filosofía como "sabiduría del amor al servicio del amor" (LEVINAS, 1974, p. 207). Finalmente, habría que examinar, en situaciones concretas, qué tipo de verdad o conocimiento

\footnotetext{
${ }^{20}$ Véase, por ejemplo, Levinas (1967).

${ }^{21}$ Tal y como lo expuso en Levinas (1987).

${ }^{22}$ A este respecto es útil considerar la analogía que establece Levinas entre su propuesta de la alteridad y el escepticismo, en este mismo capítulo 5 de $A E$, bajo el título: "Scepticisme et raison". Lo prolífico de ese apartado impide que siquiera se considere en este artículo. Para una introducción al asunto pueden verse los siguientes trabajos: Bernasconi (1991), Hutchens (2004), Morgan (2007).
} 
se produciría teniendo como fuente de significación la sustitución y cómo esta fuente exige la renovación de las conceptualizaciones tradicionales de los asuntos epistemológicos.

Por lo pronto, podría concluirse este apartado afirmando que, en efecto, la pretendida inconmensurabilidad entre verdad del desvelamiento y verdad del testimonio, incrustada en la macro discusión decir-dicho, tiene en la práctica fines metodológicos. De lo que se trataba era de subvertir la prioridad de las cuestiones, hacerlas retornar a su origen sin origen (pensado por fuera del tiempo lineal), de modo que pudiera verse cómo pese a que lo dicho traiciona el decir, este no puede más que traducirse en el dicho porque "todo se traduce en un dicho ante nosotros, todo, incluso lo inefable al precio de una traición” (LEVINAS, 1974, p. 206).

\section{Conclusión}

Quisiera sugerir, como conclusión, un caso que podría desprenderse de estas consideraciones levinasianas, a saber: el carácter intersubjetivo del conocimiento. Obviamente, este caso exigiría no solo ahondar en las tesis levinasianas sino, además, revisar discusiones contemporáneas acerca del problema en fuentes ajenas a la obra de Levinas, incluso a la fenomenología o la filosofía continental. No obstante, la simple mención tiene el propósito de señalar que, en efecto, tales tesis pueden contribuir a una racionalidad renovada.

En el marco de la discusión sobre el carácter intersubjetivo del conocimiento, la tesis levinasiana de una racionalidad que adquiere su fuente de significación en la substitución o uno-para-el-otro tiene implicaciones directas en, por lo menos, otras discusiones epistemológicas anejas: en primer lugar, con respecto a la objetividad. Según De Boer (1986, p. 96), para Levinas "no habría objetividad si no hubiera otro que me mirara, ya que el otro pone en dificultades mi espontaneidad ingenua y despierta una actitud crítica”. De esto se desprende, en segundo lugar, que los enunciados que se pretenden verdaderos no tendrían ningún sentido, ni serían necesarios, a menos que fueran evaluados por el otro; el esfuerzo por dar razones de la verdad se justifica no por la verdad misma, como se cree ingenuamente, sino porque hay una "genuina socialidad que se abre a la crítica y a la justificación de los otros" (SMITH, 1986, p. 64). Del mismo modo, en tercer lugar, la posibilidad de una auténtica objetividad, implicaría la posibilidad de la búsqueda de principios objetivos; ahora bien, el afincar la objetividad en una 
verdad del desvelamiento, ha hecho problemática su fundamentación. No es casual que haya propuestas que planteen que la racionalidad está sustentada en presupuestos irracionales ${ }^{23}$. En este punto, desde la posición levinasiana, o bien podría concederse que la objetividad se fundamenta en la Ética, o que se fundamenta en principios que se establecen por fuera de los márgenes de la verdad del desvelamiento (por ejemplo, en la significación propia de la verdad del testimonio), lo que no implica, en ninguno de los casos, apelar a la irracionalidad.

El recorrido por la distinción que establece Levinas entre verdad del desvelamiento y verdad del testimonio, si bien ha permitido reflexionar sobre las especificidades de cada tipo de verdad, también permite considerar la inextricable relación que se teje entre ellas, relación que normalmente no se tiene en cuenta (lo que no implica que no exista), y que se ha denominado en este artículo: inevitabilidad de lo dicho. Tal inevitabilidad, a mi modo de ver, posibilita no solo precaverse de adoptar posturas adversas al conocimiento, sino también motiva a buscar nuevos modos de considerar asuntos epistemológicos, entendidos estos como atinentes al conocimiento. Ambas actitudes, como se trató de mostrar en este artículo, se anclan en la literalidad misma de la propuesta levinasiana.

AGUIRRE, J. C. The inevitability of the Said. Trans/form/ação, Marília, v. 42, n. 4, p. 81-98, Out./Dez., 2019.

ABstract: This paper discusses the Levinasian thesis of the inevitability of the Said, having as its background certain epistemological issues arising from that thesis. I begin by showing the contraposition between truth of disclosure and truth of testimony, as Levinas defines them, and point out the most radical differences between the two. I then reconstruct, with subjectivity as the connecting thread, a way of relating both kinds of truth, showing how the thesis on the inevitability of the Said is relevant to epistemological discussions. I conclude by suggesting some considerations with regard to a renewed rationality.

KeYwords: Levinas. Disclosure. Epistemology. Rationality. Testimony. Truth.

${ }^{23}$ Un estudio ilustrativo a este respecto es Cíntora (2005). También De Boer (1986, p. 96) menciona la acusación que ciertos filósofos neodialécticos hicieron a Popper cuando este sostuvo que estamos comprometidos con la racionalidad, pero que ella no se puede justificar racionalmente. 


\section{Referencias}

AGUIRRE, J. C. El uno-para-el-otro o la superación ética de la ontología. Escritos, Medellín, v. 20, n. 44, p. 69-82, 2012.

BERGO, B. Levinas between ethics and politics: for the beauty that adorns the Earth. Dordrecht: Springer, 1999.

BERNASCONI, R. Skepticism in the face of philosophy. In: BERNASCONI, R.; CRITCHLEY, S. (org.). Re-reading Levinas. Bloomington: Indiana University Press, 1991. p. 149-161.

BERNASCONI, R. The third party: Levinas on intersection of the ethical and the political. Journal of the British Society for Phenomenology, London, v. 30, n. 1, p. 76-87, 1999.

BERNASCONI, R. No exit: Levinas' aporetic account of transcendence. Research in Phenomenology, Brill, v. 35, p. 101-115, 2005.

CASTRO, B. El Levinas político según Abensour. Revista de Filosofía, Santiago de Chile, v. 70, p. 45-60, 2014.

CÍNTORA, A. Los presupuestos irracionales de la racionalidad. Barcelona: Anthropos; Universidad Autónoma Metropolitana, 2005.

CRITCHLEY, S. The problem with Levinas. Editado por Alexis Dianda. Oxford: Oxford University Press, 2015.

DAVID, M. The correspondence theory of truth. In: ZALTA, E. N. (org.). The Stanford encyclopedia of philosophy (Summer Edition), 2016. Disponible en: <http://plato.stanford. edu/archives/sum2016/entries/truth-correspondence/>. Acesso em: 15 ago 2018.

DE BOER, T. An ethical transcendental philosophy. In: COHEN, R. (org.). Face to face with Levinas. New York: State University of New York, 1986. p. 83-115.

DOUKHAN, A. La epistemología de Emmanuel Levinas: de la justificación a la justicia. Anuario Colombiano de Fenomenología, Medellín, v. 8, p. 333-353, 2014.

GARCÍA-BARÓ, M. Presentación. In: LEVINAS, E. Totalidad e infinito: ensayo sobre la exterioridad. 2. ed. Salamanca: Sígueme, 2012. p. 7-11.

HUTCHENS, B. Levinas: a guide for the perplexed. New York: Continuum, 2004.

KUHN, T. The structure of scientific revolutions. 3. ed. Chicago: The University of Chicago Press, 1996.

LEVINAS, E. Enigme et phénomène. In: LEVINAS, E. En Découvrant l'existence avec Husserl et Heidegger. Paris: J. Vrin, 1967. p. 203-217.

LEVINAS, E. Vérité du devoilement et verité du témoignage. In: CASTELLI, E. (org.). Le témoignage: colloque organisé par le Centre International d'Etudes Humanistes de Rome. Paris: Aubier Montaigne, 1972. p. 101-110. 
LEVINAS, E. Autrement qu'être ou au-delà de l'essence. La Haye: Martinus Nijhoff, 1974.

LEVINAS, E. La signification et le sens. In: LEVINAS, E. Humanisme de l'autre homme. Paris: Fata Morgana, 1987. p. 15-72.

LEVINAS, E. Dios y la filosofía. Nombres, Revista de Filosofía, Córdoba, v. 8/9, p. 239269, 1996.

LEVINAS, Emmanuel. Verdad del desvelamiento y verdad del testimonio. Diálogo Filosófico, Madrid, v. 38, p. 179-188, 1997.

LEVINAS, E. The paradox of morality: an interview with Emmanuel Levinas (conducida por Tamra Wright, Peter Huges y Alison Ainley). In: BERNASCONI, R.; WOOD, D. (org.). The provocation of Levinas: rethinking the other. London: Routledge, 2003. p. 168-180.

LEVINAS, E. Totalité et infini: essai sur l'exteriorité. 10. ed. Paris: Kluwer Academic, 2006.

LEVINAS, E. Totalidad e infinito: ensayo sobre la exterioridad. 2. ed. Salamanca: Sígueme, 2012.

MEDINA, J.; WOOD, D. Truth, engagements across philosophical traditions. Oxford: Blackwell, 2005.

MORGAN, M. Discovering Levinas. Cambridge: Cambridge University Press, 2007.

NAVIA, M. De totalidad e infinito a de otro modo que ser: la huella. Episteme, Caracas, v. 30, n. 2, p. 23-31, 2010.

PERPICH, D. The ethics of Emmanuel Levinas. Stanford: Stanford University Press, 2008.

REISS, J.; SPRENGER, J. Scientific objectivity. In: ZALTA, E. N. (org.). The Stanford Encyclopedia of Philosophy (Summer Edition), 2016. Disponible en: http://plato.stanford. edu/archives/sum2016/entries/scientific-objectivity/. Acesso em: 15 ago 2018.

SMITH, S. G. Reason as one for another: moral and theoretical argument in the philosophy of Levinas. In: COHEN, R. A. (org.). Face to face with Levinas. New York: State University of New York, 1986. p. 53-71.

VAN FRAASSEN, B. C. The scientific image. Oxford: Clarendon Press, 1980.

Recebido: 25/09/2016

Aceito: 18/12/2017 